13. Zevin B, Bonrath EM, Aggarwal R, Dedy NJ, Ahmed N, Grantcharov TP. Development, feasibility, validity, and reliability of a scale for objective assessment of operative performance in laparoscopic gastric bypass surgery. J Am Coll Surg. 2013;216:955-65.e8.

14. Ericsson KA. Deliberate practice and acquisition of expert performance: a general overview. Acad Emerg Med. 2008;15:988-94.

15. Gallagher AG, Ritter EM, Satava RM. Fundamental principles of validation, and reliability: rigorous science for the assessment of surgical education and training. Surg Endosc. 2003;17:1525-9.

16. Martin JA, Regehr G, Reznick R, MacRae H, Murnaghan J, Hutchison C, et al. Objective structured assessment of technical skill (OSATS) for surgical residents. Br J Surg. 1997;84:273-8

17. Szasz P, Louridas M, Harris KA, Aggarwal R, Grantcharov TP. Assessing technical competence in surgical trainees: a systematic review. Ann Surg. 2015;261: 1046-55.
18. Regehr G, MacRae H, Reznick RK, Szalay D. Comparing the psychometric properties of checklists and global rating scales for assessing performance on a OSCE-format examination. Acad Med. 1998;73:993-7.

19. Valsamis EM, Golubic R, Glover TE, Husband H, Hussain A, Jenabzadeh AR. Modeling learning in surgical practice. J Surg Educ. 2018;75:78-87.

20. de Montbrun S, Satterthwaite L, Grantcharov TP. Setting pass scores for assessment of technical performance by surgical trainees. Br J Surg. 2016; 103:300-6.

21. Lou X, Lee R, Feins RH, Enter D, Hicks GL Jr, Verrier ED, et al. Training lessexperienced faculty improves reliability of skills assessment in cardiac surgery. $J$ Thorac Cardiovasc Surg. 2014;148:2491-6. e1-2.

Key Words: congenital heart surgery, simulation, education, assessment, 3D printing

\title{
Commentary: The time has come to measure and examine technical skills
}

\author{
James S. Tweddell, MD
}

After completion of the requirements of an Accreditation Council for Graduate Medical Education-approved thoracic surgery residency training program, potential practitioners in our specialty submit their operative experience and the evaluations of their program faculty to the American Board of Thoracic Surgery (ABTS) to sit for the Part I (written) examination. If they are successful with the written examination, they will sit for the Part II (oral) examination. For those pursuing a career in congenital heart surgery, the process begins again after completion of their congenital heart surgery training. A great deal of a Director of the ABTS's time is spent writing and revising examination questions.

From the Heart Institute and Department of Surgery, Cincinnati Children's Hospital Medical Center and the Division of Cardiothoracic Surgery, Department of Surgery, University of Cincinnati College of Medicine, Cincinnati, Ohio.

Disclosures: Author has nothing to disclose with regard to commercial support.

Received for publication Dec 22, 2019; accepted for publication Dec 23, 2019; available ahead of print Jan 12, 2020.

Address for reprints: James S. Tweddell, MD, Heart Institute, Cincinnati Children's Hospital Medical Center, 3333 Burnet Ave, Cincinnati, OH 45229 (E-mail: James.Tweddell@CCHMC.org).

J Thorac Cardiovasc Surg 2020;160:240-1

$0022-5223 / \$ 36.00$

Copyright $($ c 2020 by The American Association for Thoracic Surgery

http://dx.doi.org/10.1016/j.jtcvs.2019.12.091

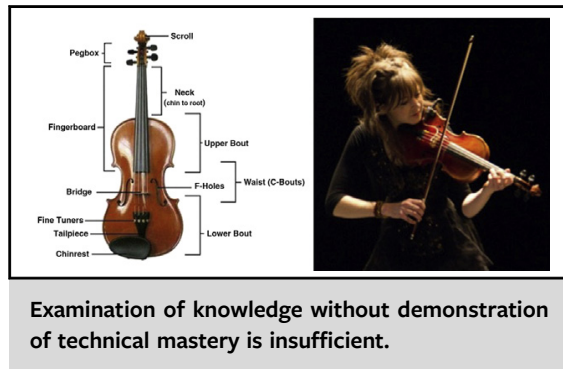

CENTRAL MESSAGE

Technical performance is essential for successful congenital heart surgery, and it is time to start measuring and examining surgical skills.

The examination questions are carefully chosen, and each year's examination is reviewed before and after the examinations are taken. The performance of each question is evaluated to make certain it is correct and helps to predict the outcome of the examination. The aim of the written examination is to gauge the candidate's fund of knowledge. The oral examinations are admittedly more subjective but are given by several examiners, and the aim is to gauge the candidates' thought processes and decision-making ability. Having been a part of this process, I will say that the ABTS Directors succeed admirably in developing fair and objective examination processes that measure fund of knowledge and decision-making ability of the candidates.

However, cardiothoracic surgery and, especially, 


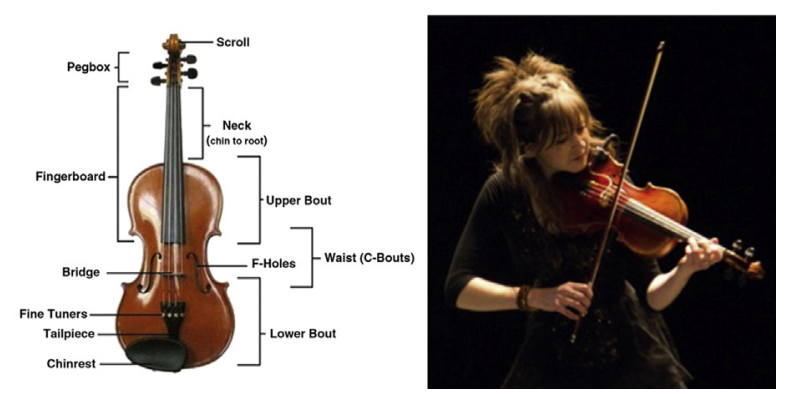

FIGURE 1. While we might expect a music student to know the parts of a violin, the examination process would not be complete without a performance to demonstrate technical mastery. The examination process for congenital heart surgeons should include not only knowledge and decision making but technical skills as well. Used with permission from Wikipedia (https://en.wikipedia.org/wiki/Violin).

congenital heart surgery, arguably are medical specialties in which technical performance is an absolute necessity for successful patient outcome. In recent years, it has become more difficult to train congenital heart surgeons. Ours is an era in which the simplest cases, atrial septal defects and patent arterial duct ligations, are few and far between. We have to begin to train candidates with more complex patients. Furthermore, we live in an era of increased transparency in which our results are more closely scrutinized. These factors create pressures that can limit a congenital heart surgery trainee's hands-on experience and their preparation for independent practice.

The idea of a "learning curve," a required number of attempts before being able to reliably achieve the anticipated outcome, is well understood and accepted in medical training, but I suspect would not be acceptable to the public. None of us would accept a learning curve for commercial airline pilots or nuclear power plant engineers. While there is no substitute for hands-on experience, we must find ways to teach residents technical skills where human lives are not placed in peril. A number of strategies have been used successfully; training on animal hearts, virtual reality simulation, and as demonstrated in the paper by Hussein and colleagues, 3-dimensional models. ${ }^{1-4}$ Each of these has its advantages and shortcomings. The current simulations can be complimentary. Excision and mobilization of coronary buttons can be demonstrated on a fresh cadaveric pig heart, but the anatomy of transposition is better understood with a model.

Deficiency in our examination process cannot be ignored. In arguably the most technically demanding surgical specialty, we have no systemic and validated method to measure technical performance in our trainees. We rely exclusively on the subjective assessment of the trainee's faculty, most importantly the program director. This is quite a contrast to other professions, where technical performance is essential. We wouldn't graduate a student from a music conservatory after only a discussion of how they would perform a piece of music, we would require a technically demanding performance that demonstrated mastery of their instrument (Figure 1). We might have written examinations for food safety for culinary art students, but we would not consider graduating them without preparation of a dish that demonstrated their skill and knowledge. We do, however, graduate surgeons without an objective examination of their technical skills. "If you can't measure it, you can't manage it" is a quotation variably attributed to both Peter Drucker and W. Edwards Deming. We need better assessment and objective goals of technical performance in our trainees. If we aren't measuring our candidates' technical performance, we aren't managing it, and we cannot be certain we are producing a reliable product; technically competent surgeons. This work by Hussein and colleagues and that of others validating technical skills measurement is a first step. ${ }^{4,5}$ To be sure, we are still at the beginning of the era of simulation in congenital heart surgery and can expect improved fidelity in the future. Simulation as part of our teaching strategy should be combined with examination of our candidates' technical abilities. Standardized skills station examinations, direct observation of surgical performance, or submission of videos of "benchmark" operations are methods that are immediately available. The addition of technical performance examinations will add substantially to the work of the ABTS, program directors, and our trainees, but filling this gap in our certifying process is essential.

\section{References}

1. Mavroudis CD, Mavroudis C, Jacobs JP, DeCampli WM, Tweddell JS. Simulation and deliberate practice in a porcine model for congenital heart surgery training Ann Thorac Surg. 2018;105:637-43.

2. Friedl R, Preisack MB, Klas W, Rose T, Stracke S, Quast KJ, et al. Virtual reality and 3D visualizations in heart surgery education. Heart Surg Forum. 2002;5: E17-21.

3. Valdis M, Chu MW, Schlachta C, Kiaii B. Evaluation of robotic cardiac surgery simulation training: a randomized controlled trial. J Thorac Cardiovasc Surg. 2016;151:1498-505.e1492.

4. Hussein N, Lim A, Honjo O, Haller C, Coles JG, Van Arsdell G, et al. Development and validation of a procedure-specific assessment tool for hands-on surgical training (HOST) in congenital heart surgery. J Thorac Cardiovasc Surg. 2020;160: 229-40.e1.

5. Lee R, Enter D, Lou X, Feins RH, Hicks GL, Gasparri M, et al. The Join Council on Thoracic Surgery Education coronary artery assessment tool has high interrater reliability. Ann Thorac Surg. 2013;95:2064-9; discussion 2069-2070. 